\title{
Research Paper: Investigation of the Accidents Recorded at an Emergency Management Center Using the Pareto Chart: A Cross-Sectional Study in Gonabad, Iran, During 2014-2016
}

\author{
Mohammad Hosein Beheshti ${ }^{1}$, Roohalah Hajizadeh², Somayeh Farhang Dehghan ${ }^{3}$, Reza Aghababaei ${ }^{4}$, Sayed Mohammad Jafari ${ }^{5}$ \\ Alireza Koohpaei ${ }^{6,7^{*}}$ \\ 1. Department of Occupational Health, School of Health, Gonabad University of Medical Sciences, Gonabad, Iran \\ 2. Work Health Research Center, Qom University of Medical Sciences, Qom, Iran. \\ 3. Department of Occupational Health Engineering, School of Public Health, Shahid Beheshti University of Medical Sciences, Tehran, Iran. \\ 4. Department of Occupational Health Engineering, School of Health, Hamadan University of Medical Sciences, Hamadan, Iran. \\ 5. Department of Occupational Health Engineering, School of Medicine, Khatam Al-Nabieen University, Kabul, Afghanistan. \\ 6. Department of Occupational Health Engineering, School of Health, Qom University of Medical Sciences, Qom, Iran. \\ 7. Occupational Health Research Center, Qom University of Medical Sciences, Qom, Iran.
}

Article info:

Received: 02 Nov. 2017

Accepted: 28 Feb. 2018

\section{Keywords:}

Pareto charts, Accident analysis, Emergency centers
Citation: Beheshti MH, Hajizadeh R, Farhang Dehghan S, Aghababaei R, Jafari SM, Koohpaei A. Investigation of the Accidents Recorded at an Emergency Management Center Using the Pareto Chart: A Cross-Sectional Study in Gonabad, Iran, During 2014-2016. Health in Emergencies and Disasters Quarterly. 2018; 3(3):143-150. https://doi.org/10.29252/NRIP.HDQ.3.3.143

doi : https://doi.org/10.29252/NRIP.HDQ.3.3.143 


\section{Introduction}

oday, government allocates large portions of resources to accidents and disaster man1 agement. Every day media reports various incidents that occur around the world. Climate changes, human handicaps in nature, and rapid technological growth have increased the level of human vulnerability and the occurrence of accidents [1].

The statistics show the growth rate of around the world is causing financial losses and casualties to nations every year. In the last decade, nearly one billion people in the world, about one-sixth of the world's population, have been directly or indirectly affected by the disaster. Iran is one of the countries with the highest casualties. According to the World Health Organization (WHO) annual report, more than 60 million people were injured in road traffic crashes [2], and most road traffic crashes involved youngsters [3]. Road traffic crashes, in addition to physical and mental injuries, cause capital and economic losses [4].

Millions of people suffer from various types of disabilities due to road traffic crashes every year, which leads to the loss of active human resources and millions of hours of useful work [5]. The damage caused by road traffic crashes in human societies is far greater than the damage caused by diseases such as cancer, cardiovascular disease, Alzheimer's and AIDS [6]. According to the WHO, worldwide 3.5 million people die every year in an accident. In addition, a huge amount of resources allocated to the health sector is used to compensate for damages caused by accidents [7]. In addition to economic loss, the psychological and emotional impact of accidents on victims and their families is also unforgivable [8]. However, the studies show that $98 \%$ accidents can be prevented [9].

To examine the conditions in any particular context is the first step to identifying problems and implementing appropriate and proper planning. Findings from Knight et al. study revealed most of the road traffic deaths involved illiterate men in the age group of group 21-40 years [10]. Fam et al. in a research conducted in Tehran, reported that $12.7 \%$ victims of traffic accidents were motorcyclists [11]. Shibata and Fukuda, in its study to investigate the risk factors in motor vehicle accidents, reported that driving without license, driving under the influence, speeding, riding without helmets and seatbelts are leading causes of death in road traffic crashes [12]. Shankar and Mannering have proposed five levels for determining the severity of injuries in a five-year study of motor vehicle accidents, which include financial losses, probable damage, obvious damage, damage leading to disability and death. They have also stated that the severity of injuries depends on factors such as environment, status of the rider, features of the vehicle, and characteristics of the driver [13].

One of the major problems in the application and implementation of management and engineering measures is the lack of knowledge about causes and its impact on accidents. To provide a solution to eliminate or reduce incidents, it is important to identify and investigate the causes behind them. Therefore, providing reality-based control strategies is only possible if critical points and factors affecting the occurrence of accidents are identified. Hence, the allocation of cost-control in a useful and scientific way requires research into accident records at government departments and agencies. In the recent years, relatively a huge amount of money has been spent to control and reduce injuries caused by accidents inside and outside the city. However, there is no significant reduction in the safety and reduction of injuries caused by accidents. The most important reason for this issue is spending costs without taking into account the priorities and key factors affecting the occurrence of accidents. On the other hand, few studies are being undertaken to identify the causes that contribute to the incidents.

In this study, we have tried to investigate the records at the Gonabad Medical Accident and Emergency Management Center during the period 2014-2017 in an analytical and descriptive manner using the Pareto chart and identify the reasons behind the accidents using the Pareto chart, and can propose and implement effective and targeted control strategies.

\section{Materials and Methods}

This descriptive-analytic study analyzed records of accidents at the Gonabad Emergency Management Center from 2014 to 2016 using Pareto chart. Pareto chart, named after Italian scientist Wilfred Pareto who observed that $80 \%$ of the wealth is received by $20 \%$ of the people in Italy. Pareto charts illustrate frequency distribution of classified descriptive data. The chart places the class on horizontal axis and frequencies on the vertical axis. To draw the Pareto chart, all steps are required to draw a column graph. The events are represented in descending order and the cumulative record is represented by the line. By using this method, the area with the maximum problems $(80 \%)$ is determined [14]. 
After determining the frequency, the chart is drawn based on frequency and percentage of inclusion. To achieve frequency, it is necessary to prepare a registration form based on needs and analyze them. Although calculations can be done manually but using the software increases speed and accuracy [14].

In this study, we investigated the data during the period of 2014-2016, and other variables such as number of crashes, causes, age and sex of crash victims, time, marital status, type of incident, drugged driving, which is separated for incidents related to transportation and unrelated to transportation. The research received ethical approval by the Research Ethics Committee of Gonabad University of Medical Sciences (Code of Ethics: IR.GMU.REC.1394.58). Finally, data were analyzed using the SPSS software version 21 and Excel 2010 with the help of Minitab v.16 software (Figure 1). The data were analyzed using the correlation coefficient and logistic regression test at a significant level of 5\%.

\section{Results}

In this study, 25414 incidents, recorded at the Emergency Management Center of Gonabad city, Iran, were investigated. The type of accident and age group are shown in Figure 2. Based on the findings of this study, the highest rate of the accidents $(39.79 \%)$ was observed for individuals aged between 0-10 years. In addition, $62.3 \%$ of the victims were in the age group of $40-55$,
55-75, and 0-10 years. It was observed that the cardiovascular events and blood pressure were the most common incidents. The transportation-related accidents and cardiovascular events were $16 \%$ and $10 \%$, respectively.

Figure 3 shows the Pareto chart of transport accidents based on the type of vehicle, and Pareto chart for transportation accidents on the basis of injured people. According to the Pareto charts, more than $90 \%$ accidents are related to motorcycles and cars. The analysis of the inured people in transportation accidents indicates that the highest percentage of injuries was related to the driver, passengers and pedestrians.

The treatment of the injured people and the outcome of the mission are shown in Figure 4. Among the adopted therapeutic measures, prescription of medications was the highest at the $39.4 \%$. The outcome of the missions of the emergency center is often different. After categorizing these results and analyzing them, it was observed that $46.6 \%$ of the mission results in the transfer of injured to the health centers. Outpatients were ranked second with $32.8 \%$ of the mission's results. Other accidents recorded in the emergency management center were poisoning and burns. The causes of burns were divided into several categories; nearly $80 \%(76.4 \%)$ burns were caused by hot and flammable liquids. Food, medicine and drug caused more than $80 \%$ of poisoning incidences. Pareto chart about the type of poisoning and burn incidents are shown in Figure 5.

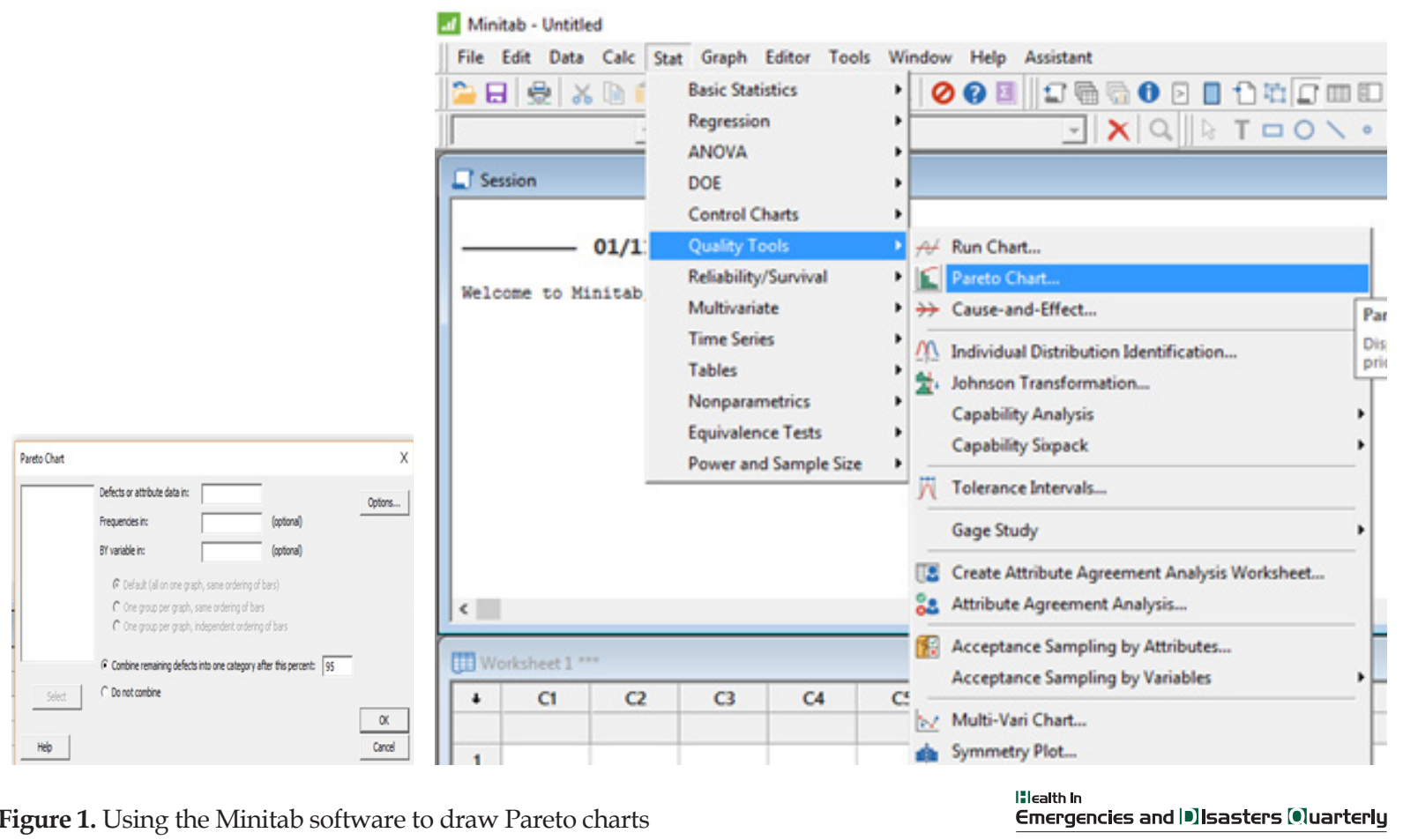


Chart A

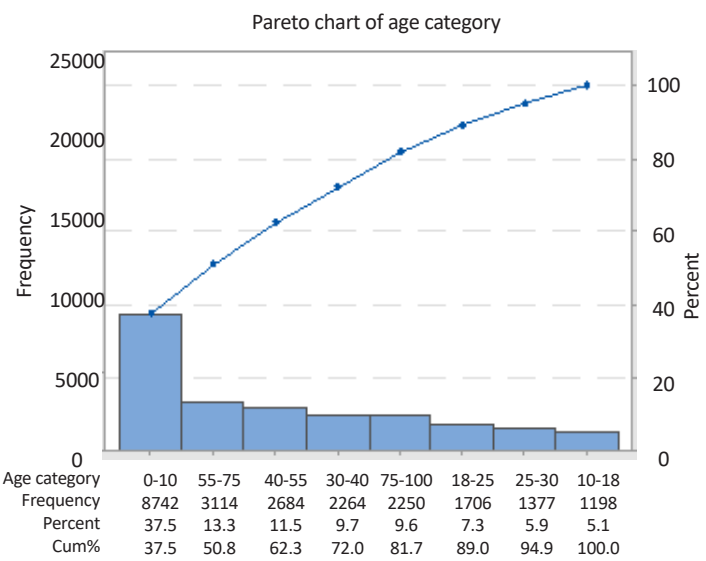

Chart B

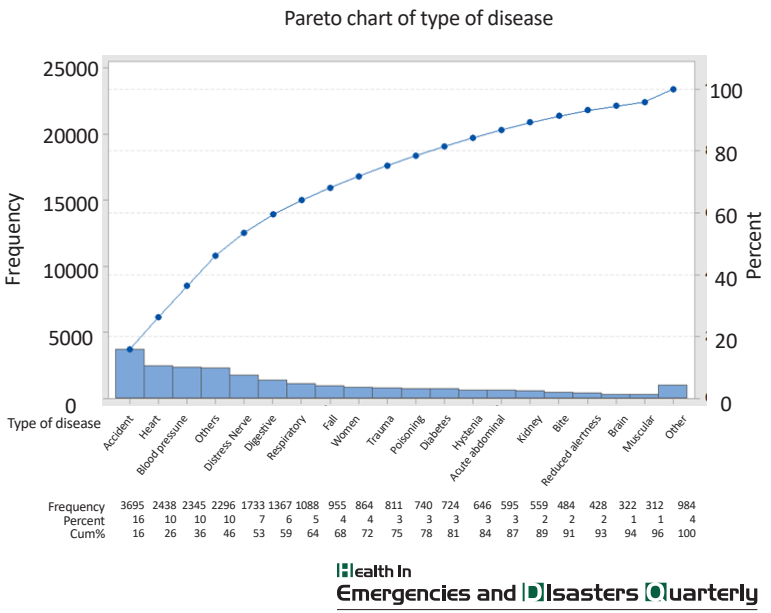

Figure 2. Pareto chart of accidents in terms of age (chart A) and by type of accident (chart B)

Figure 6 presents Pareto chart of accidents based on the type of injury. Transportation and non-traffic accidents led to various injuries and damages. Most of the lesions were tenderness-related with $36.2 \%$ occurrence. Also, more than $80 \%$ of the injuries include tenderness, scratches, tears, fractures, and bleeding.

The distribution of accidents, recorded by the emergency center, is classified according to the months of the year and analyzed using the Pareto chart. March had the highest percentage of accidents and December had the lowest. In almost identical results regarding the frequencies of accidents in different months, it was observed that it was highest during the spring and lowest during the winter. Further details are shown in Figure 7.

\section{Discussion}

The findings of this study indicate that from 2014 to 2016, 25, 414 incidents were recorded in the emergency center of Gonabad city, and as per the results of this

Chart A

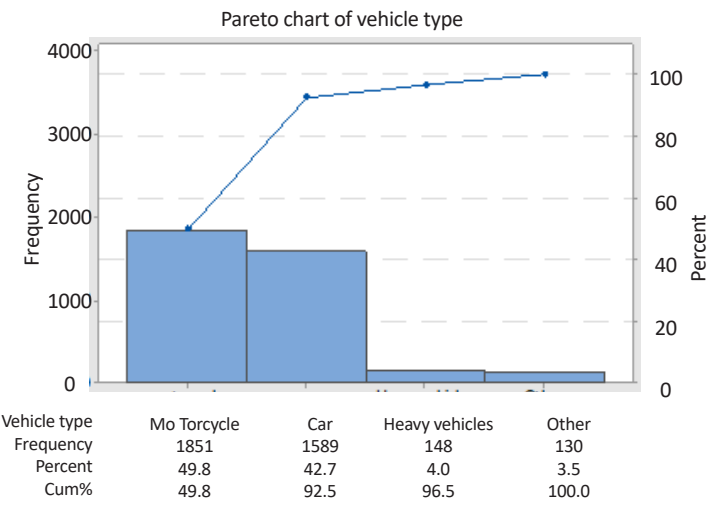

study, $39.79 \%$ of the accidents involved 0 to 10 years age group, the highest based on the age group. The earlier studies conducted in Yazd, Iran, revealed that most of the incidents involved children under the age of 6 [14]. According to Neghab and et al. study in Fars province, Iran, the frequent incidents involved children under the age of 5 [15]. According to the studies, most of the children-related incidents are caused by highrisk environment and lack of growth. By educating and sensitizing parents on the importance of providing care for children and offering safety education program for kindergarten and school children, it can be prevented to a certain extent. Also, the results showed that 40 to 55 and 55 to 75 age groups had the highest rates of crashes. And after road traffic crashes, the second most common cause of accidents was heart diseases, including high blood pressure. It is obvious that older adults are more prone to heart diseases and hypertension, and need better health care. The Masoumi et al. study conducted in Kermanshah Heart Hospital, Iran,

Chart B

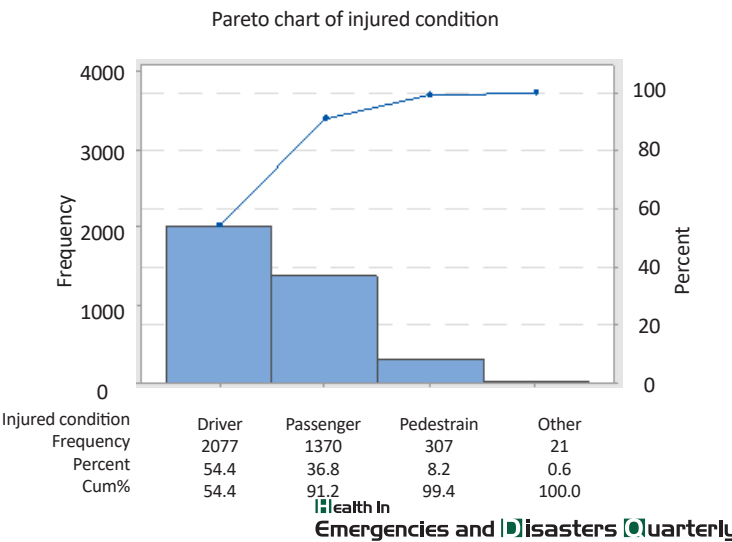

Figure 3. Pareto charts of transport accidents based on the type of vehicle (chart A) and the injured person (chart B) 
Chart A

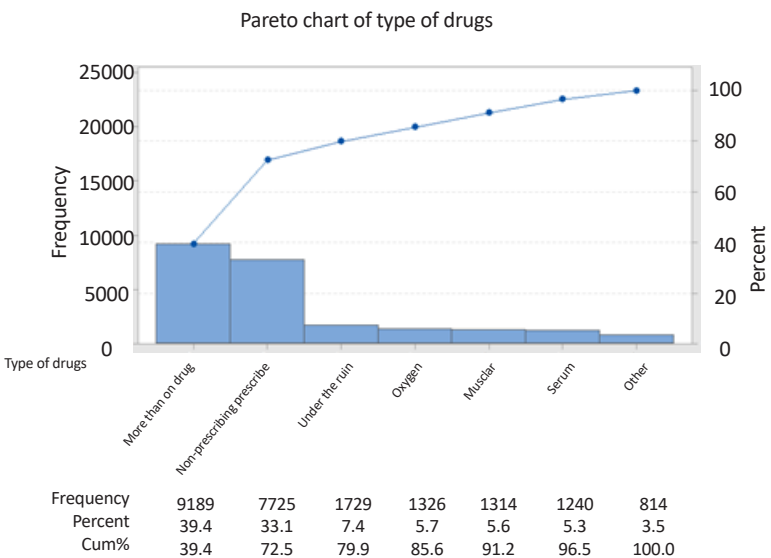

Chart B

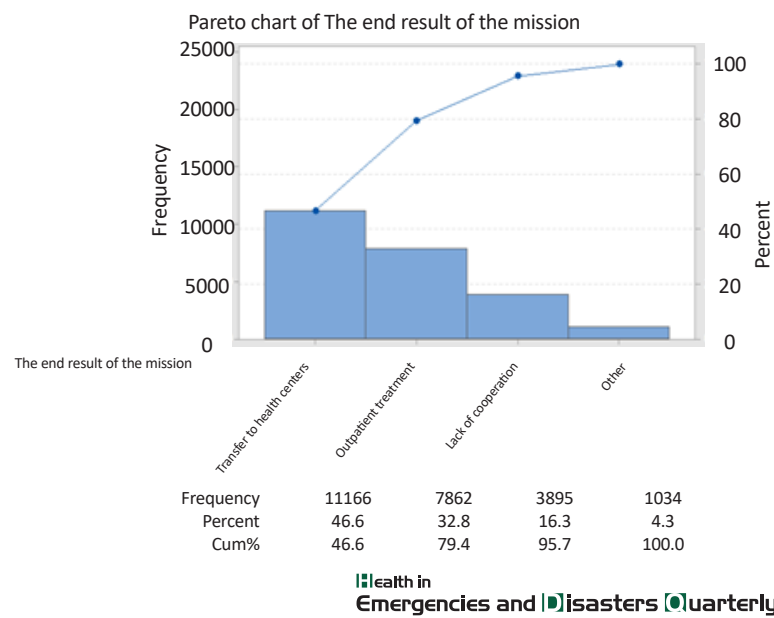

Figure 4. Pareto charts of accidents based on the type of treatment for the injured people (chart A) and the outcome of the mission (chart B)

found that majority of the patients with cardiovascular disease were in the age group of 60 and 69 years and $35.5 \%$ of them had hypertension [16]. Therefore, for prevention and control of such diseases, executive and educational programs should be considered.

The results of this study showed that transportation accidents accounted for the highest percentage (17.61\%) and it is consistent with previous studies. For example, Naghavi's study reported that in Iran in 2002, 275,000 were hospitalized and there were 19,100 road traffic deaths [17]. Shojaee et al. reported that rate of death in transportation accidents in Chaharmahal Bakhtiari province, Iran, was 41 per 100,000 people [18] and this study showed that the largest number of accidents were related to driver and passengers. In the study of Taghipour in

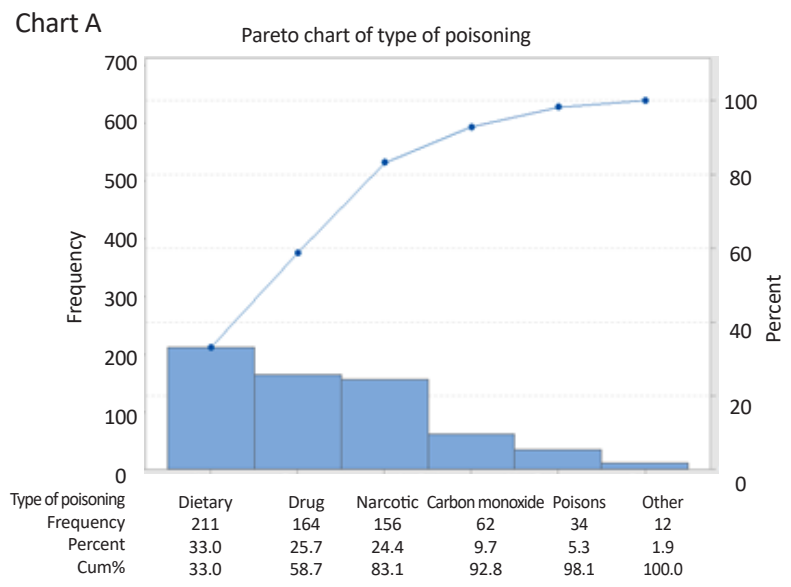

Yazd, Iran vehicle-pedestrian accidents were the most common type of accident at $39.8 \%$ [19].

Loss due to accidents is 1.3 percent of GDP in developing countries. According to the media reports, and World Health Organization, Iran has the highest number of deaths due to road traffic crashes [20]. The fact that the driver and the passengers have the highest crash rates, it is important to review the safety majors such as seat belts, airbags, brakes and the body of the vehicle, and the vehicle manufacturers should take responsibility for ensuring international safety standards.

According to the findings of the study, the emergency center provided various therapeutic interventions for the injured people. The $39.4 \%$ medications prescription and $0.08 \%$ inhalation therapy were the highest and lowest type of action among the therapeutic measures.

Chart B

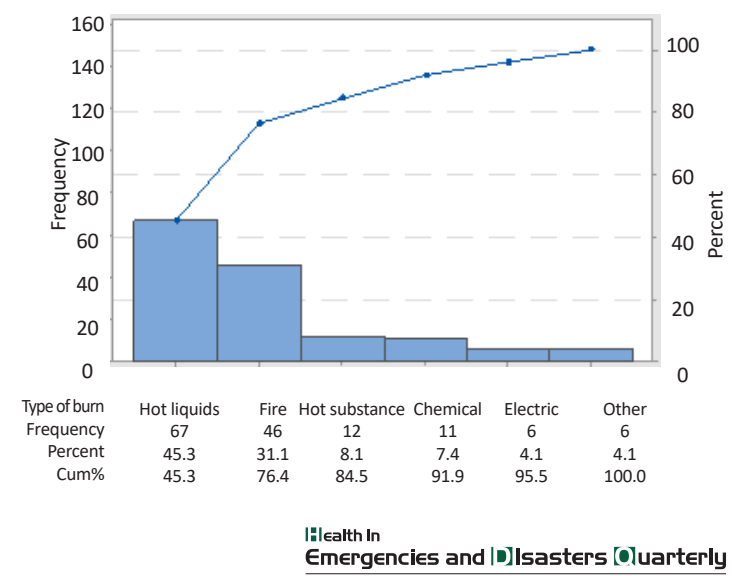

Figure 5. Pareto chart of type of poisoning incidents (chart A) and burn incidents (Chart B) 


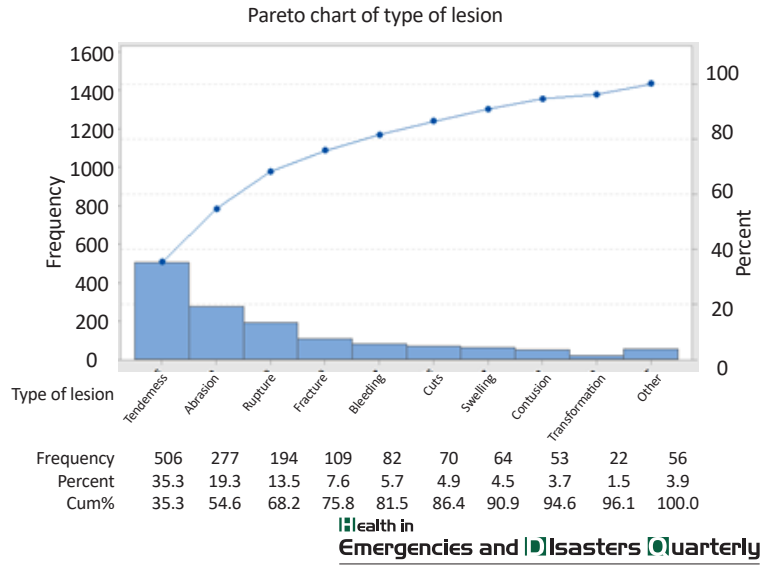

Figure 6. Pareto chart of accidents based on the type of injury

Also, $46.6 \%$ of emergency missions included transfer to health centers and $32.8 \%$ was outpatient treatment. According to Naghavi, of the 9 million reported accidents, $1,100,000$ were hospitalized, and 4 million were outpatient treatment and 37,000 lost their lives [17].

In the unrelated-transportation accidents, the most burns were related to hot liquids (49.5\%) and fire (28.98\%). An eight-year-old study in Kuwait revealed $67 \%$ [21] burns due to hot liquids, which is $61 \%$ in Saudi Arabia, 44\% in Afghanistan and 53\% in Shiraz, Iran $[22,23]$. In order to reduce the burn cases, parents and children and others should be provided information on treating and preventing burns; effective safety education to increase safety practices at home and work places; medical first aid measures through media, schools and health centers. Also people should be informed to take necessary precautions while cooking methods and using appliances such as samovars and kettles.

Chart A

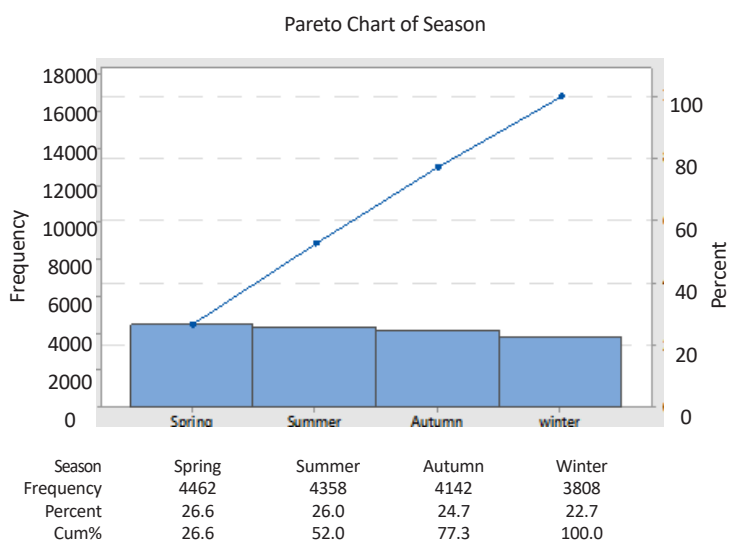

The analysis of poisoning accidents revealed that food poisoning, medicine poisoning and drug poisoning accounted for more than $80 \%$ of total poisoning cases. According to the Shakeri et al. study, the most common causes of poisoning are poisoning due to drug and narcotic substances (drug substance $64.6 \%$ and narcotics $22.9 \%$ ) [24], which is in agreement with the results of this study. Since the most important measure for preventing diseases and poisonings is changing people's lifestyles. It seems that empowering people through education and compliance with rules and regulations can prevent food, pharmaceutical and drug poisoning.

Both related and non-related transport accidents cause various damages and injuries, and most of the injuries are related to tenderness with the frequency of $36.2 \%$ and about $80 \%$ of the lesions include tenderness, scratches, tears, fractures, and bleeding. The distribution of events recorded by the emergency center is classified according to the months of the year and analyzed using the Pareto chart. It was found that March recorded the highest percentage of accidents, and December had the lowest. In almost identical results with regards to frequency distribution of events in different months, it was observed that the spring had the highest percentage of accidents and the winter had the lowest. In a study conducted in Kermanshah, Iran, the highest accidents occurred during spring [25]. It can be concluded that the reason for increased risk of accidents at the beginning of the year and during the spring may be due to the increase in the number of trips and because a large number of people indulge in outdoor activities during $\mathrm{Norooz}$ holiday. It is possible to prevent accidents by improving safety culture and increasing safety awareness through social media, television, radio, and internet.

Chart B

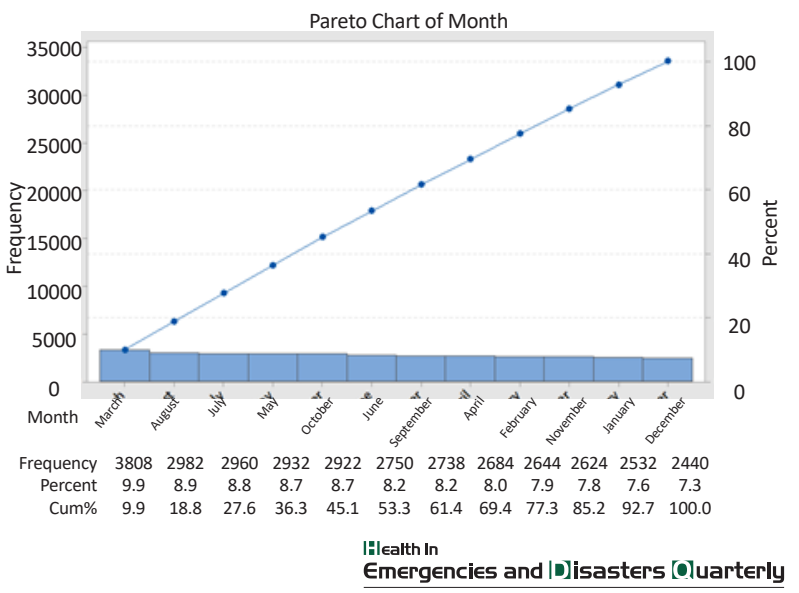

Figure 7. Pareto chart distribution of accident based on season (chart A) and month (chart B) 


\section{Conclusion}

Since road traffic crashes are more involved than nonrelated ones, close partnership among economic, social and political authorities is needed to educate drivers about safe driving and implement an advanced traffic management system in Iran. Head and neck injuries are common in road traffic crashes; therefore, the use of seat belts and baby car seats and the use of helmet while driving motorcycle can greatly prevent such lesions. Traffic accidents like many heart diseases are preventable and it requires improving public awareness about the importance of observing traffic safety principles and enhancing street safety. Developing effective emergency medical care in emergency centers can be crucial in reducing traffic deaths.

\section{Acknowledgments}

This study has been funded and supported by Gonabad University of Medical Sciences; Grant no. 1394/ P/522/1.

\section{Conflict of Interest}

The authors declare no conflicts of interest.

\section{References}

[1] Khanke HR. [Hospital preparedness in national disaster accidents (Persian)]. Tehran: University of Social Welfare and Rehabilitation Sciences Publications; 2012.

[2] Pfortmueller CA, Marti M, Kunz M, Lindner G, Exadaktylos AK. Injury severity and mortality of adult zebra crosswalk and non-zebra crosswalk road crossing accidents: A crosssectional analysis. PLoS ONE. 2014; 9(3):e90835. doi: 10.1371/ journal.pone.0090835

[3] Gicquel L, Ordonneau P, Blot E, Toillon C, Ingrand P, Romo L. Description of various factors contributing to traffic accidents in youth and measures proposed to alleviate recurrence. Frontiers in Psychiatry. 2017; 8:94. doi: 10.3389/ fpsyt.2017.00094

[4] Brauer RL. Safety and health for engineers. New Jersey: John Wiley \& Sons; 2016.

[5] Moloudi A, Kalhori M, Hoseini Z, Rawshani D. [Epidemiology of acute coronary syndrome in Kermanshah (Persian)]. Journal of Kermanshah University of Medical Sciences. 2006; 10(30):252-7.

[6] Breuer J, Höffer EM, Hummitzsch W. Rate of occupational accidents in the mining industry since 1950: A successful approach to prevention policy. Journal of Safety Research. 2002; 33(1):129-41. doi: 10.1016/s0022-4375(02)00009-9
[7] Macedo AC, Silva IL. Analysis of occupational accidents in Portugal between 1992 and 2001. Safety Science. 2005; 43(56):269-86. doi: 10.1016/j.ssci.2005.06.004

[8] Hämäläinen P, Takala J, Saarela KL. Global estimates of occupational accidents. Safety Science. 2006; 44(2):137-56. doi 10.1016/j.ssci.2005.08.017

[9] Ericson CA . Hazard analysis techniques for system safety. New Jersey: John Wiley \& Sons; 2005. doi: 10.1002/0471739421

[10] Knight S, Junkins EP, Lightfoot AC, Cazier CF, Olson LM. Injuries sustained by students in shop class. Pediatrics. 2000; 106(1):10-3. doi: 10.1542/ peds.106.1.10

[11] Akbari ME, Naghavi M, Soori H. Epidemiology of deaths from injuries in the Islamic Republic of Iran. Eastern Mediterranean Health Journal. 2006; 12:382-90

[12] Azadeh A, Nouri J, Fam IM. The impacts of total system design factors on human performance in power plants. American Journal of Applied Sciences. 2005; 2(9):1301-4. doi: 10.3844/ajassp.2005.1301.1304

[13] International Labour Organization. Safety, health and welfare on construction sites: A training manual. Geneva: International Labour Organization; 1999.

[14] Mazloomi SS, Falahzadeh H. [The prevalence of injuries in people under 20 years in Yazd (Persian)]. Payesh. 2001; 2(4):21-5.

[15] Neghab M, Habibi M, Rajaeifard A, Choubineh AR. [Home accidents in Shiraz during a 3-year Period (2000-2002) (Persian)]. Journal of Kermanshah University of Medical Sciences. 2008; 11(4):428-40.

[16] Masoomi M, Saidi MR, Piri F, Abdoli G. [Epidemiology of coronary artery disease in Kermanshah (Persian)]. Journal Kermanshah of Medical Sciences University. 2004; 8(2):37-46.

[17] Naghavi M, Jafari N, Alaedin F, Jafari ME. [Epidemiology of injuries and external causes (accidents) in Iran (Persian)]. Paper presented at the $1^{\text {st }}$ National Congress of Epidemiology and Health Services. 24-26 December 2002; Boshehr, Iran.

[18] Shojaee M, Ahmadian S, Raeisi R, Mossavian R, Ghanbari AK, Ghanbari L. [The survey of view inadvertant accidents in Chaharmahal Bakhtiari Province in 1386 Year (Persian)]. Paper presented at the $2^{\text {nd }}$ National Congress on Injury Prevention \& Safety Promotion in Disaster. 21-23 February 2009, Kerman, Iran.

[19] Panahi F, Khoshmohabat H, Taghipour HR, Firoozabadi NH, Moharamzad Y, Abbasi AR. [Causes and severity of fatal injuries in autopsies of victims of fatal traffic accidents (Persian)]. Journal of Shahid Sadoughi University of Medical Sciences. 2010; 17(5):358-64.

[20] Zargar M, Modaghegh MHS, Rezaishiraz H. Urban injuries in Tehran: Demography of trauma patients and evaluation of trauma care. Injury. 2001; 32(8):613-7. doi: 10.1016/ s0020-1383(1)00029-8

[21] Calder F. Four years of burn injuries in a Red Cross hospital in Afghanistan. Burns. 2002; 28(6):563-8. doi: 10.1016/ s0305-4179(02)00071-2

[22] Al-Shehri M. The pattern of paediatric burn injuries in Southwestern, Saudi Arabia. West African Journal of Medicine. 2005; 23(4):294-9. doi: 10.4314/wajm.v23i4.28144 
[23] Ansari Lari M, Askarian M. Epidemiology of burns presenting to an emergency department in Shiraz, South Iran. Burns. 2003; 29(6):579-81. doi: 10.1016/s0305-4179(03)00066-4

[24] Shakeri MT, Afshari R, Aghajani H, Dinmohamadi E, Hadianfar A. [Study geographical distribution of poisoning cases referred to the emergency department of Imam-Reza Hospital Mashhad: 2013 (Persian)]. Medical Journal of Mashhad University of Medical Sciences. 2016; 59(3):171-8.

[25] Almasi A, Hashemeyan A. [State street accident in Kermanshah (Persian)]. Journal of Kermanshah University of Medical Sciences. 2002; 8(1):47-54. 